\title{
PARA ALÉM DOS GÊNEROS: HERBERTO HELDER
}

\author{
Fernando Paixão \\ Universidade de São Paulo
}

O presente ensaio propõe uma reflexão sobre a questão dos gêneros poéticos híbridos -poema em prosa e prosa poética-, a partir da escrita imaginosa e ousada do escritor português Herberto Helder. Poeta dotado de gosto pela experimentação, em alguns de seus textos torna-se reveladora a ambiguidade que envolve forma e conteúdo, prosa e poesia.

Palavras-chave: Helberto Helder, poesia portuguesa, gêneros híbridos, poema em prosa.

Na rica constelação da poesia portuguesa contemporânea, a figura de Herberto Helder certamente consta como a de um astro de primeira grandeza. Nascido em 1930 na ilha da Madeira, este escritor tem produzido uma obra poética em que a nossa língua é levada a um estado primoroso, cantante, vocacionada para a evocação de imagens intensas e essenciais.

O autor teve uma infância difícil em sua terra natal, com a morte precoce da mãe quando ele tinha oito anos de idade. Estudou na ilha até os 16, quando se mudou para Lisboa a fim de cursar o liceu. A partir de então, teve uma vida errante conduzida pela busca de experiências e desde cedo decidido a dedicar-se intensamente à escrita literária.

No início dos anos 1950, Helder começa a publicar os primeiros poemas, depois de uma frustrada passagem pelos cursos de Direito e de Filologia Românica. Nessa década, frequenta com assiduidade o grupo de escritores do Café Gelo, onde vem a conviver com Mario Cesariny de 


\section{Fernando Paixão}

Vasconcelos (bardo do surrealismo português), Luis Pacheco, Manuel de Lima e outros.

Em 1958 é publicado o seu primeiro livro, $O$ amor em visita. Viaja por vários países da Europa e, para sobreviver, trabalha em serviços diversos: empregado de cervejaria, carregador de caminhão, ajudante de pasteleiro e guia de marinheiros em bairros de prostituição, entre outros (Marinho 11-17). Deportado da Antuérpia em 1960, volta a Lisboa e retoma as publicações literárias.

Sucede então uma série de livros marcados por uma poética de fundo elegíaco, em mescla com o gosto pelo experimentalismo e pelas vozes extremas. Vieram $A$ colher na boca (1961), Lugar (1962), Poemacto (1963), Eletronicolirica (1964), Humus (1967), até chegar a Apresentação do rosto (1968), quando sua obra é apreendida pela censura salazarista. Figura radical no contexto da época, Helder chega a sofrer um processo judicial por conta da publicação do libro A filosofia na alcova, do Marquês de Sade, na qual havia colaborado, durante os anos 1960.

A década seguinte é marcada por uma viagem à África, onde acaba sofrendo um grave acidente de automóvel, em 1972. Volta para Lisboa e, um ano depois, publica a primeira edição da Poesia toda ${ }^{1}$, obra em que ficam evidenciadas a alta qualidade e a coerência do seu trabalho. Em estado de inquietação permanente, ele insiste até hoje em fazer mudanças no texto sempre que ocorrem novas edições dessa compilação.

A primeira incursão na tentativa de "superar a dicotomia prosa-poesia" ocorre em 1963, com Os passos em volta. ${ }^{2}$ Livro intrigante - escrito durante viagem de outsider pela Europa -, reúne textos claramente inspirados pelo gosto do experimentalismo com a linguagem. São prosas de inspiração semelhante aos poemas, recorrendo à elaboração

\footnotetext{
${ }^{1}$ A primeira edição dos poemas reunidos de Herberto Helder foi publicada pela editora Plátano, em dois volumes, em 1973. A edição seguinte, pela editora Assírio e Alvim, saiu em 1981, e vem tendo sucessivas edições modificadas.

2 A primeira edição deste livro saiu pela editora Portugália, em 1963; atualmente é publicado pela Assírio e Alvim.
} 
conceitual e à ênfase, mas desta vez voltadas sobretudo para o foco do narrador quase sempre em "crise" com a sua circunstância.

Do ponto de vista do gênero, ainda que sejam híbridos, ficam mais próximos do conto. ${ }^{3}$ Contos à beira da poesia, pode-se dizer. Afinados com o universo do fantástico e de costas para a dita realidade. Em mais de um aspecto, lembram uma atitude rimbaudiana diante do mundo, denunciando a hipocrisia social e a solidão individual em confronto os mecanismos dominantes. Como tudo o que Helder escreve, são textos dotados de alta voltagem imagética.

O poema em prosa, por sua vez, aparece mais tarde na obra do autor, por meio de um livro inteiramente dedicado ao gênero: Retrato em movimento, de $1967 .{ }^{4}$ Nota-se nesse trabalho uma poética próxima da que anima os poemas em versos, havendo mesmo uma repetição dos temas motivadores: amores e terrores; minérios e pássaros; mãos; a criança e o sol; as palavras, as pedras e outras imagens ligadas a elementos essenciais do corpo e da natureza.

Exemplo dessa dicção aparece no texto de abertura do conjunto, que eleva a escrita a uma atmosfera de êxtase:

Dedicatória - a uma devagarosa mulher de onde surgem os dedos, dez e queimados por uma forte delicadeza. Atrás, o monumento do seu vestido ocidental - erguido e curvo. E o vestido trabalha desde o fundo e de dentro - como uma raiz branca - para o aparecimento da cabeça. A paisagem posterior é de livros, todos eles de costas voltadas, dominados pelas ardentes pancadas das suas letras. Algures vai passar a lua cavalgando a luz de um só lado, impressamente no papel redondo do céu. Os peixes são também números e tremem de sutileza à volta do lugar ameaçado. E o pescoço da mulher é uma letra de catedral, a letra de um alfabeto morto que um dia se encontrará noutro planeta - arcaica e reinventada (Poesia toda 377).

${ }^{4}$ Herberto Helder publicou poemas em prosa com os livros Retrato em movimento (1967) e Vocação animal (1971); reorganizados e acrescidos de outros textos, reaparecem na obra poética de 1981 com o título único de Retrato em movimento. 


\section{Fernando Paixão}

Praticamente a cada frase, o imaginário sofre contínuas mudanças, evocando elementos excêntricos, fragmentos de imagens, associações diversas trazidas para o rodamoinho do pensamento poético. $\mathrm{Na}$ condição de leitores, somos igualmente assaltados de sugestões visuais e sonoras induzidas pelo ardor do texto.

Apostando na força mobilizadora de uma imaginação onírica e exaltada, a evocação de pensamentos em torno da simbólica feminina estende-se até o fim do poema, sem perder o encantamento:

E aí está essa mulher que se move na paisagem escorregadia -
rodeada por casas arrancadas pela raiz, voltadas no ar. Penso
muito em todas essas letras simplesmente pousadas no A da sua
cor vermelha, tal como a maçã que se põe - quieta e morosa -
sobre o quanto vai ser de madura, e isso vindo da sua
obscuridade, da sua salva infância de maçã. E ocupamo-nos
novamente na bela insensatez. Como o alfabeto. A lua cavalga a
grandeza da mulher, as letras aparecem, impressas no muro
desse vestido branco ocidental, letras como estátuas de animais.
A mulher vai ter uma cabeça de cão aberta em basalto - os
cabelos lavrados no osso como as linhas numa página. E a
cabeça de cão sorri implantadamente no alfabeto, apoiada no
ocidente do vestido. E é um livro (Poesia toda 377).

Em tom de evocação, a mulher ganha uma dedicatória associada a cores, letras, luas, maçãs, cabeça de cão e outras tantas coisas. O poeta faz dessas imagens uma energia sonora e plástica, dando margem a aparições arbitrárias que equivalem a uma miragem da "bela insensatez".

Como um colar de imagens, suspenso no fio tênue do ritmo, compõe-se uma cosmogonia que define e mobiliza qualidades em nome da figura central: "a lua cavalga a grandeza da mulher, as letras aparecem, impressas no muro desse vestido branco ocidental, letras como estátuas de animais". Eixo organizador da imaginação, o elemento feminino cumpre a função de um tema primitivo, gerador de intensidade poética.

Maria Lucia Dal Farra, que escreveu um primoroso estudo sobre o autor, oferece uma explicação para essa ocorrência obsessiva. Segundo ela, a representação da mulher aparece na obra de Helder "tomada, de um lado, como parceira do 
ritual das transmutações e, de outro, como iniciadora" (147). Justifica-se, assim, que esteja associada tanto à amada quanto à mãe (recorrente em vários poemas), pois em ambas as referências o que importa é a evocação das origens. Embora sejam representações distintas, mobilizam um sentimento análogo.

Há que se notar ainda a semelhança dos temas evocados como a criança, a água, a árvore, as cores e outros tantos - e que servem material para a imaginação do escritor, expressa em versos ou não. Tanto nos poemas em prosa como nos outros, chama a atenção o encadeamento delirante de imagens que veio a se tornar a característica central do seu estilo.

No entanto, há uma sutil diferença entre os gêneros, que merece ser comentada. No caso da produção em versos do autor, sobretudo nos livros publicados até o início da década de 1970, nota-se uma composição rítmica marcada por frases, ora compondo um verso por inteiro, ora sendo entrecortadas em versos arbitrários.

Com o intuito de enfatizar alguma das imagens ou o som das palavras, o autor recorre ao enjambement como elemento de realce para certos fragmentos do imaginário. Neste caso, a cesura cumpre função auxiliar ao ritmo do poema, como neste trecho de "Lugar último":

\section{(...)}

Uma mulher passou quando eu dormia ou acordava.

Era uma luz molhada.

Estava ao cimo como lágrimas, estava com folhas à tona da idade.

Passou uma delicadeza, uma mulher que ficou.

Existiu um campo transviado.

Uma alagada adivinhação. Por cima abruptamente

uma - pancada na noite dos órgãos.

A noite é não ter amor senão

em luzes.

Com uma pedra sobre a boca.

A pedra sente a boca, a solidão sente

o homem. Digo que um homem beija 


\section{Fernando Paixão}

interiormente a boca.

Mas era uma mulher que morria, uma mulher que agora nascia altamente.

Um lúcido campo morto.

(...) (Poesia toda 186)

Vislumbrada a partir de qualidades advindas do corpo, a figura feminina, ela mesma, constitui-se fonte das imagens: "Estava ao cimo como lágrimas, estava/ com folhas à tona da idade. (...) Mas era uma mulher que morria,/ uma mulher que agora nascia altamente./ Um lúcido campo morto".

Até mesmo o uso de verbos de estado (ser, estar, passar, existir, morrer, nascer) reforçam a emanação das qualidades humanas a partir do seu centro. Essas qualidades, aliás, estão apresentadas por meio de um rol de frases afirmativas, com frequência recorrendo ao paralelismo para fortalecer a musicalidade geral do poema. O recorte entre os versos desdobra a imagem poética em fragmentos que podem ser percebidos com maior clareza e força.

Já nos poemas em prosa - talvez induzidos por um desejo de compensar a ausência do enjambement -, alguns deles enfatizam visivelmente a vertigem de imagens para obter o efeito desejado. Disposto em linhas inteiras, o fluxo poético apoia-se, sobretudo, no contraste das frases e dos conteúdos. A surpresa das associações sugeridas ajuda a compor o resultado.

A reforçar esse traço, boa parte dos poemas compõe-se de parágrafo único, figurando um bloco compacto e coruscante no atrito entre os elementos evocados. No ato da leitura, somos conduzidos em meio a um fluxo vertiginoso de pensamentos e sensações.

Para exemplificar, pode-se recorrer a qualquer texto do conjunto intitulado "Os animais carnívoros":

A água anda a uma velocidade branca, porém tu dizes: também sei que o amor é sinistro - e entretanto eu tomo drogas para celebrar um espaço louco, as redes amadurecem para a cerimônia ritual da pesca e os peixes amadurecem para a sua morte fervente - também vi as máquinas caminharem ao lado das colinas bêbadas, diz alguém devagar para não ser ouvido, de súbito há um lugar que foge pelas trevas dentro, mas de ti o que conheço é um lenço de grandes pétalas encostado ao rosto, e o 
coração é minado pelo som das próprias pancadas, porém tu dizes: o amor é uma coisa silenciosa, e logo a tua voz cai no silêncio com a cauda enrolada, mas ainda se ouvem as canções do ocidente percorridas de anis e de cantáridas, e mais abaixo as guitarras meditam a música, e a luz inclina-se para sermos redondos - oh silêncio: geometria absoluta - e o teu corpo pousa na delicadeza, é quando a beladona é uma flor que não conheço, e tu dizes: o amor é incorrigível como um sol de pé - então chega o tempo da transformação das imagens, e eu amo-te como o sal e a areia se deitam juntos, e nas terras do interior a ciência é esta: tuas ancas violentas, o teu cabelo frio (Poesia toda 421).

O perigoso tema do amor, tão difícil de ser abordado com originalidade, chega aos nossos ouvidos e olhos com um renovado frescor de linguagem, tal é o sopro encantado do poema. Deparamos com um fluxo de palavras que termina por harmonizar imagens aleatórias, mas com a capacidade de urdir um sentido comum a todo o organismo do texto. Contribui para isso a recorrência à expressão "tu dizes", que surge por três vezes no poema (no início, no meio e ao fim), e cumpre uma função organizadora.

Verifica-se, nessa harmonização de imagens aleatórias, a estreita familiaridade do estilo de Helder com o ideário e a estética do surrealismo, conforme salientam alguns estudos dedicados ao autor. No entanto, a influência surrealista não chega a dar conta da singularidade desses textos, e pode até mesmo turvar o entendimento de outros aspectos igualmente importantes.

Parece-nos que a riqueza dos poemas em prosa de Helder tem menos a ver com a escrita automática e as técnicas do surrealismo do que com a intensidade simbólica que essa escrita é capaz de acionar. Basta retomar algumas frases do poema anterior para comprovar o efeito: "as redes amadurecem para a cerimônia ritual da pesca e os peixes amadurecem para a sua morte fervente"; "mas de ti o que conheço é um lenço de grandes pétalas encostado ao rosto"; "as guitarras meditam a música, e a luz inclina-se para sermos redondos"; "eu amo-te como o sal e a areia se deitam juntos".

Ao recorrer a uma imaginação extraordinária e evocativa, os poemas se veem dotados de uma carga simbólica que vai 


\section{Fernando Paixão}

além do inconsciente pessoal enfatizado pelos experimentos de André Breton e seus contemporâneos. No caso do poeta português, interessa mais visitar as lonjuras dos nexos e das aproximações. Como se o autor estivesse lidando com uma combinatória livre e infinita - qualidade indiscutível da sua poesia.

É com a publicação de Photomaton \& Vox que Herberto Helder apresenta o seu trabalho mais inusitado e inclassificável. Lançado em 1979, reúne 59 textos, inéditos até então ou coligidos de publicações anteriores. Constitui um verdadeiro mosaico de pequenos textos e poemas (inclusive alguns em versos) que formulam um continuum em que a reflexão se nutre de imagens intencionalmente poéticas, conduzidas a um ponto tal, que fica difícil saber a que gênero pertencem.

Desde o início é um livro de configuração livre, pois não apresenta sumário nem qualquer frase explicativa sobre a obra. Dela, consta apenas o logotipo e o endereço da editora acompanhando uma sequência de textos dotados de um brilho estilístico evidente. Ao que parece, a proposta reside justamente nessa ausência de indicação de caminhos de leitura. Cada leitor que faça a sua.

Quanto aos textos, apresentam um tom estranho ao senso comum, sem se enquadrarem nem mesmo dentro das fronteiras amplas do poema em prosa. Ou, pelo menos, sem se identificar de imediato com essa forma de escrita. $\mathrm{Na}$ verdade, resultam de uma escrita que se identifica com a busca experimental, interessada em alargar o seu campo de significação.

Voltada para o senso plástico das imagens sugeridas, a linguagem do autor promove intencionalmente um raciocínio abstrato e simbólico, seja para recuperar determinada experiência vivida no passado - o acidente sofrido na África, por exemplo, que reaparece em vários momentos -, seja para enunciar conceitos e metáforas ligadas ao corpo e à natureza. 
Há ainda em Photomaton \& Vox uma série grande de textos cujo tema é a poesia mesma, fonte de obsessões e potencialidades diversas. Esses textos cumprem uma função de laboratório de ideias para um autor tão inquieto, angustiado por importantes questões; podem até mesmo ser entendidos como apontamentos de alquimista.

Para se ter uma melhor noção desse ideário e dos seus recursos, nada melhor do que recorrer a um desses textos:

\section{Introdução ao cotidiano}

Às vezes as coisas desatam a crescer numa espécie de sentido ao contrário. Desenvolvem-se em dois planos, movem-se em lugares diferentes. Entre eles bate um coração, uma alma, um motor. Aqui é que estão a unidade e o sentido - o senso, o contra-senso. Imaginemos uma planta com as raízes no ar e a flor debaixo da terra - mas raízes eficazes, e uma flor perfeitamente organizada. A máquina desta planta é um milagre de energia. Foi tocada pelo sopro da alegria criadora. Faz coisas simétricas, assimétricas - maravilhas circulatórias e respiratórias: estruturas vivas. Mas está de cabeça para baixo. Não se integra nas matemáticas gerais. Falha nas relações. É outro milagre - um rasgão, uma oposição, uma subversão: um clarão. O conjunto estremece, abalado por uma luz nova. Todas as coisas refluem então para este centro devorador, este aparelho centrípeto. $\mathrm{O}$ contra-senso é o senso. Falo do cotidiano absolutamente real, realizado. Vou contar uma história. Havia uma rapariga que era maior de um lado que de outro. Cortaremthe um bocado do lado maior: foi demais. Ficou maior do lado que era primitivamente menor. Tornaram a cortar. Foram cortando e cortando. O objetivo era este: criar um ser normal. Não conseguiam. A rapariga acabou por desaparecer, de tão cortada nos dois lados. Só algumas pessoas compreenderam.

Não me venham com teorias, estou farto. Acontecimentos, seres, objetos, lugares. A coluna vertebral disto tudo. A posição vertical - eis o que me parece justo. Se se anda com a cabeça e se põe o chapéu nos pés, não é a coluna vertebral que tem culpa. Trata-se de uma fé antípoda. Porque o erro pode estar em andar com os pés e pôr o chapéu na cabeça. De qualquer maneira, é magnífico ver uma flor ter delicadeza debaixo da terra. Bem: pode tomar-se um espelho e colocá-lo em frente das coisas. $\mathrm{Na}$ melhor das hipóteses, onde era esquerdo fica direito, e viceversa. Pode acontecer tudo negro noutros casos. Porque as coisas são negras. Dormimos ou estamos acordados conforme a escolha. Atenção. É uma espécie de espetáculo. Vem anunciado nos jornais. Não se inventou, apenas se tornou mais forte a 


\section{Fernando Paixão}

pancada do martelo. Sim, na cabeça. Chama-se a isto malícia ou intenção.

Segue. Sempre. (Photomaton 88-90)

Ao sabor de um fluxo de consciência, nota-se no texto um propósito de desconstrução mental visando recusar o hábito cristalizado e o imaginário amortecido. Acena ainda para um nexo de vida desvendado apenas "quando as coisas desatam a crescer numa espécie de sentido ao contrário".

Desenvolve um imaginário mediado por um contexto radical de imagens (uma planta de raiz e flor invertidas; a mulher cortada em sua parte maior, sucessivamente, até desaparecer), mas também por um pensamento que se propõe filosófico, ainda que em ataque contra os equívocos da razão.

Suas palavras não deixam margem a dúvidas: "Não me venham com teorias, estou farto. Acontecimentos, seres, objetos, lugares. (...) Se se anda com a cabeça e se põe o chapéu nos pés, não é a coluna vertebral que tem culpa. Trata-se de uma fé antípoda", afirma o poeta. E complementa: "Porque o erro pode estar em andar com os pés e pôr o chapéu na cabeça".

Temos, pois, uma argumentação que sustenta uma inversão de valores, promovendo uma tensão de pontos de vista que se sobrepõe ao plano do enunciado. Por força da ênfase das frases, o texto conduz a discussão de modo a remetê-la para o campo da ética. Interessa ao poeta justamente promover a corrosão da mentalidade repetitiva do cotidiano e, num sentido mais amplo, a superação de uma forma alienada de perceber a realidade. Dormir ou ficar acordado, como diz o texto, é uma questão de escolha.

No que se refere à questão do gênero, portanto, é natural que apareça a dúvida sobre como enquadrar esse texto. Trata-se de um poema em prosa? Prosa poética? Prosa curta? E talvez a melhor resposta para isso seja aquela que em verdade não responde, deixa em suspenso o juízo e abre espaço para outras variantes.

O fato é que a qualidade maior desses textos, e do imaginário neles implicado, está justamente em não permitir 
uma classificação imediata do seu conteúdo ou forma. Fortes e feéricos, reflexivos e altamente metafóricos - escapam aos rótulos da percepção literária habitual.

Ainda assim, alguém poderá argumentar que o núcleo do texto apoia-se na figura da menina cortada de um lado e do outro, eixo de todo o discurso. Embora a história apareça apenas em um segmento, a situação é narrada com o espírito de parábola, distante de qualquer viés realista.

$\mathrm{O}$ autor maneja uma série de imagens e metáforas (planta, raízes, mulher cortada, coluna vertebral, martelo), conseguindo imprimir um colorido poético ao texto, que extrapola o âmbito das especulações filosóficas. Ora, isso justificaria justamente o argumento de que "Introdução ao cotidiano" pertence à categoria do poema em prosa. Mesmo mantendo a inclinação filosófica, sua aposta maior vai em direção da poesia.

Mas também será possível a contrapartida de considerar o mesmo texto em outra direção, como uma anotação abstrata, interessante sem dúvida, mas que ultrapassa o campo poético e resvala para o tom reflexivo. Considerá-lo, pois, como um poema em prosa, deixaria de dar importância a esse viés político e ativista que anima a voz do poeta.

Qual dos dois argumentos terá mais razão? Fica em aberto. Photomaton \& Vox destaca-se por ser um livro que cultiva a radicalidade da visão estética associada a uma escrita original. Livro raro e inquietante, é difícil de ser categorizado. Contribui para esse espírito a mistura de assuntos, ora de inspiração autobiográfica (o acidente de carro, a infância e a adolescência na ilha, as primeiras viagens etc.), ora tratando dos dilemas éticos e formais da poesia.

De maneira contundente, Helder posiciona-se numa linhagem de autores que acreditam na palavra poética enquanto expressão da identidade pessoal, e não foge ao desafio: "Esta/ espécie de crime que é escrever uma frase 


\section{Fernando Paixão}

que seja/ uma pessoa magnificada"5. Em sua visão, as esferas da vida e da poesia mantêm relação estreita entre si ${ }^{6}$.

De modo muito particular, este livro atualiza o impasse estético da poética contemporânea, revelando um autor destemido e desejoso em acordar conteúdos simbólicos adormecidos ou desprezados na vida ordinária. Sem se fixar nos modelos típicos de prosa e poesia, Photomaton \& Vox mobiliza uma imaginação poderosa e capaz de diluir as fronteiras entre os gêneros. Obra rara e de enigma permanente.

\section{Obras citadas:}

Dal Farra, Maria Lucia. A alquimia da linguagem: leitura da cosmogonia poética de Herberto Helder. Lisboa: Imprensa nacional, Casa da moeda, 1986.

Helder, Herberto. O amor em visita. Lisboa: Contraponto, 1958.

---. "Entrevista." Jornal de Letras e Artes 27 maio 1964: 23-24.

---. "Mensagem ao jornal." Jornal de Letras e Artes nov. 1988: 4.

---. Photomaton \& Vox. Lisboa: Assírio e Alvim, 1987.

---. Poesia toda. Lisboa: Assírio e Alvim, 1981.

Marinho, Maria de Fátima. Herberto Helder: a obra e o homem. Lisboa: Arcádia, 1982.

\footnotetext{
5 Versos de abertura do livro - pois o texto inicial é em versos e ironicamente se intitula "(é uma dedicatória)" (Photomaton 7).

6 Tornou-se conhecida sua recusa a conceder entrevistas e a receber prêmios literários, crítico que tem sido da institucionalização do texto literário. Em 1988, recusou o prêmio do Pen Clube, que resolveu the outorgar uma homenagem pelos 25 anos de sua poesia, causando muitos comentários a respeito de sua atitude. . À época, respondeu ao prêmio com uma mensagem ao Jornal de Letras: "O Pen Clube arranjou um prêmio que arranjou um júri que arranjou um autor. Tudo na voz ativa, exceto o autor, passivamente apanhado no meio dos arranjos..." ("Mensagem ao jornal" 4.)
} 